\title{
RECOVERY OF THE IPSILATERAL OCULOTECTAL PROJECTION FOLLOWING NERVE CRUSH IN THE FROG: EVIDENCE THAT RETINAL AFFERENTS MAKE SYNAPSES AT ABNORMAL TECTAL LOCATIONS ${ }^{1}$
}

\author{
JAMES ADAMSON, ${ }^{2}$ JOHN BURKE, AND PAUL GROBSTEIN ${ }^{3}$ \\ Department of Pharmacological and Physiological Sciences, University of Chicago, Chicago, Illinois 60637
}

Received February 21, 1984; Revised April 23, 1984; Accepted April 27, 1984

\begin{abstract}
The ipsilateral oculotectal projection in the frog is a topographic mapping of the binocular part of the visual field of one eye on the ipsilateral tectal lobe. The underlying neuronal circuitry consists of the topographic, crossed retinotectal projection and an intertectal pathway which relays information from a given point in one tectal lobe to the visually corresponding point in the other. During optic nerve regeneration, there is a period when the terminals of retinotectal afferents are found at abnormal locations in the opposite tectal lobe. Whether they form functional synapses at this time is not known. If so, one would expect to observe correlated abnormalities in the ipsilateral oculotectal projection. To determine whether such abnormalities exist, we have made parallel electrophysiological studies of the recovery of the retinotectal and ipsilateral oculotectal projections following crush of one optic nerve.

The earliest stage of recovery was characterized by a lack of significant topographic order in the retinotectal projection and by the absence of a physiologically observable ipsilateral projection. Within a short time, the retinotectal projection became topographically organized and a similarly organized ipsilateral projection appeared. While topographic, the retinotectal projection at intermediate times was abnormal in that the multiunit receptive fields recorded at individual tectal loci were greatly enlarged. Multiunit receptive fields were similarly enlarged in the ipsilateral projection. In addition, some ipsilateral fields included areas of visual space not normally represented in the projection. The abnormalities in both projections subsequently disappeared over the same time course. Throughout recovery there was a high correlation between multiunit receptive field sizes in the contralateral tectal lobe and those at visually corresponding points in the ipsilateral tectal lobe.

Enlarged multiunit receptive fields in the contralateral tectal lobe could not be accounted for in terms of optical or retinal abnormalities since single unit receptive field sizes were normal. Nor could they be accounted for in terms of changes in recording characteristics since simultaneously recorded fields activated by the undisturbed eye were normally sized. We conclude that the enlarged fields in the contralateral tectal lobe indicate the presence at individual tectal loci of afferents from wider than normal retinal regions. Similar considerations ruled out optical, retinal, and recording abnormalities as the explanation for the enlarged multiunit receptive fields in the ipsilateral tectal lobe. The enlarged ipsilateral multiunit receptive fields were recorded only at tectal loci normally involved in the ipsilateral projection and were locally abolished by local lesions in the opposite tectal lobe. These and other observations mentioned make it unlikely that the enlarged ipsilateral multiunit receptive fields result from abnormalities in the intertectal relay itself. Single unit receptive field sizes in the ipsilateral projection were enlarged, as would be expected if there was abnormally wide functional convergence onto elements of the intertectal relay. We conclude that during the recovery of the ipsilateral projection there are abnormalities of the kind expected if retinal terminals form functional synapses at abnormal locations in the contralateral tectal lobe.
\end{abstract}

The recovery of the topographically ordered, crossed retinotectal projection during optic nerve regeneration in the frog has been extensively studied electrophysiologically. A recent de-

\footnotetext{
${ }^{1}$ This work was supported by United States Public Health Service Grants EY-01658 and Research Career Development Award EY-00057, National Science Foundation Grant BNS-7914122, and an Alfred P. Sloan Fellowship to P. G. J. A. was supported by United States Public Health Service Grant TO5 GMO 7281. We thank J. Heberle for help
}

scription of the recovery process (Humphrey and Beazley, 1982) differs somewhat from earlier ones (Gaze and Jacobson, 1963; in preparing figures, and M. Hollyday, C. Comer, and T. Masino for helpful comments.

${ }_{2}^{2}$ Present address: Department of Neurosurgery, Mount Sinai Medical Center, New York, NY 10029.

${ }^{3}$ To whom correspondence should be sent, at Department of Pharmacological and Physiological Sciences, University of Chicago, 947 East 58th Street, Chicago, IL 60637. 
Gaze and Keating, 1970a), but there is general agreement that the normal distribution of ganglion cell terminals in the tectum is not directly re-established. Instead, the projection during early stages of regeneration is disordered and there is a progressive recovery of normal topographic organization. Recently, Fujisawa et al. (1982) have provided anatomical evidence for abnormally distributed ganglion cell terminals during regeneration in amphibians. However, there is little information which bears on the question of whether the abnormally located terminals actually form functional synapses. It thus remains possible, despite the evidence for mislocated terminals, that ganglion cells are, during regeneration, quite specific in their synaptic selectivity, as originally suggested by Sperry (see Sperry, 1963). Alternatively, it may be the case that optic nerve regeneration involves not only shifting of terminals but making and breaking of synapses as well.

In addition to the direct retinal projection to the opposite tectal lobe, there is in the frog an indirect topographic projection from each eye to the ipsilateral tectal lobe. This "ipsilateral oculo-tectal projection" (Grobstein and Comer, 1983), like the crossed retinotectal projection, is known to be re-established following interruption of the optic nerve (Gaze and Keating, 1970b). The process by which this occurs has not been studied and is of interest in connection with the question of the degree of synaptic selectivity displayed by regenerating retinal ganglion cell axons. The anatomical substrate of the ipsilateral projection consists of the direct, crossed retinotectal projection and an intertectal pathway through the nucleus isthmi which relays information from a given locus in one tectal lobe to the visually corresponding locus in the other (Grobstein and Comer, 1983; see also references therein). Hence, if abnormally located retinal terminals form functional synapses in the contralateral tectal lobe, this might be expected to result in correlated abnormalities in the visual field represented at the corresponding point in the ipsilateral tectal lobe (see Fig. 1). To determine whether such correlated abnormalities exist, we have made parallel electrophysiological studies of recovery of both the direct retinotectal projection and the ipsilateral oculotectal projection following optic nerve interruption. A preliminary report of some of these results has appeared (Adamson and Grobstein, 1982).

\section{Materials and Methods}

Rana pipiens ranging from $2 \frac{1 / 2}{2}$ to 4 inches in snout-to-vent length were obtained from commercial suppliers and were used in these experiments. All surgery and electrophysiological recording were carried out under anesthesia induced by injection of tricaine methanesulfonate (Sigma Chemical Co.) into the dorsal lympth saes or leg muscles and maintained with supplemental injections as necessary.

Experimental animals were subjected to unilateral optic nerve interruption by crushing the nerve just distal to its exit from the skull. The nerve was exposed via an incision in the roof of the mouth and interrupted without destruction of the surrounding sheath by repeated crushing with a fine pair of forceps until a transparent zone appeared. Crushing rather than cutting was employed to try to reduce the incidence of misregeneration to the wrong tectal lobe (Gaze and Keating, 1970a). While it is not possible to be certain with a crush that all axons were severed, our results, like those of others using the same procedure, indicate that substantial if not complete functional interruption is achieved with this method. Following surgery animals were maintained separately at room temperature.

Projections from both eyes to both tectal lobes in experimental and in normal animals were mapped using standard electrophysiological techniques (Gaze and Jacobson, 1963; Grobstein et al., 1980) with some modifications. The frogs were centered in an Aimark projection perimeter using body rather than retinal coordinates (Grobstein et al., 1980); a central visual field point thus corresponded to a point directly in front of or behind the frog rather than to a point on the optic axis of one eye. In most cases both front and back visual hemifields were mapped, necessitating centering of animals facing first into and then away from the perimeter.

Low impedance tungsten microelectrodes were used to record activity in superficial tectal layers at an array of locations $200 \mu \mathrm{m}$ apart and covering the dorsal surface of both tectal lobes. Recordings were made within 100 to $200 \mu \mathrm{m}$ of the tectal surface; activity at these levels typically consisted of multiple single units as well as an unresolved background, all displaying predominantly response characteristics of type 1 and 2 ganglion cells (Maturana et al., 1960; Keating and Gaze, 1970). At each recording site the locations in visual space where stimuli evoked activity were determined. Stimuli consisted of small spots of light projected onto the perimeter in a darkened room. Spots of various sizes and intensities were both flashed and moved slowly in order to define not simply the location where the maximum response was obtained but rather the borders of a region in visual space within which stimuli produced an excitatory response. Such borders were not difficult to locate and were relatively independent of spot size and intensity so long as the problem of light scattering was taken into account. Borders were frequently checked by moving a dark spot in a lighted room without significant differences being observed. At each tectal location the existence and organization of input from each eye was studied independently by covering first one and then the other eye with an opaque occluder. The effectiveness of the occlusion was checked by verifying that stimuli failed to elicit responses when both eyes were covered.

In several animals we studied receptive field sizes of single units by adjusting electrode position and filtering characteristics of an audio monitor until the discharge of one unit in the multiunit recording became clearly distinguishable from that of others. The single units, which have smaller receptive fields, were mapped not directly on the perimeter but rather on a tangent screen. Again, comparable boundaries were observed both with light spots projected on the screen in a darkened room and with dark spots moved against the white background under room illumination.

The dependence of activity evoked by the ipsilateral eye on the integrity of the contralateral tectal lobe was tested in several experimental frogs by using two microelectrodes located so as to record from visually corresponding points in the two tectal lobes. Visual correspondence was established by positioning the electrodes in such a way that the receptive fields for activity recorded on the two were the same when mapped through the normal eye. Once this was accomplished, the electrode in the tectal lobe contralateral to the experimental eye was switched from a recording circuit to a current passing circuit. A small electrolytic lesion was produced by passing $10 \mu \mathrm{A}$ of electrode-negative current for $10 \mathrm{sec}$, after which the presence or absence of elicited activity in the ipsilateral tectal lobe was tested. In a few cases, when residual activity was still present in the ipsilateral tectal lobe, an additional $10 \mathrm{sec}$ of current was passed. Subsequent to the lesion, recordings were made in the vicinity of the original clectrode positions in both tectal lobes to characterize the extent of tectum affected.

\section{Results}

\section{Contralateral and ipsilateral maps in normal animals}

Electrophysiological characterization of the projections from one eye to the contralateral and ipsilateral tectal lobes is normally based on recordings at an array of locations in superficial tectal layers and determination, at each, of the locations in visual space where stimuli elicit activity (see discussion in Hunt and Jacobson, 1974). At any given point, the evoked activity is normally from a number of units recorded simultaneously. There is good reason to believe that recordings in the contralateral tectal lobe are largely from the terminal arbors of retinal afferents (Lettvin et al., 1959; Maturana et al., 1960; George and Marks, 1974). It seems likely that recordings in the ipsilateral tectal lobe are similarly from terminal arbors (Gruberg and Lettvin, 1980), presumably those of crossed isthmotectal afferents, but the evidence in this case is less complete. The general practice in mapping projections has been to identify with each tectal locus a point in space, the point which is at the center of the region of space represented by the aggregate receptive fields of the simultaneously recorded single units. This practice has been followed in prior work on regeneration 


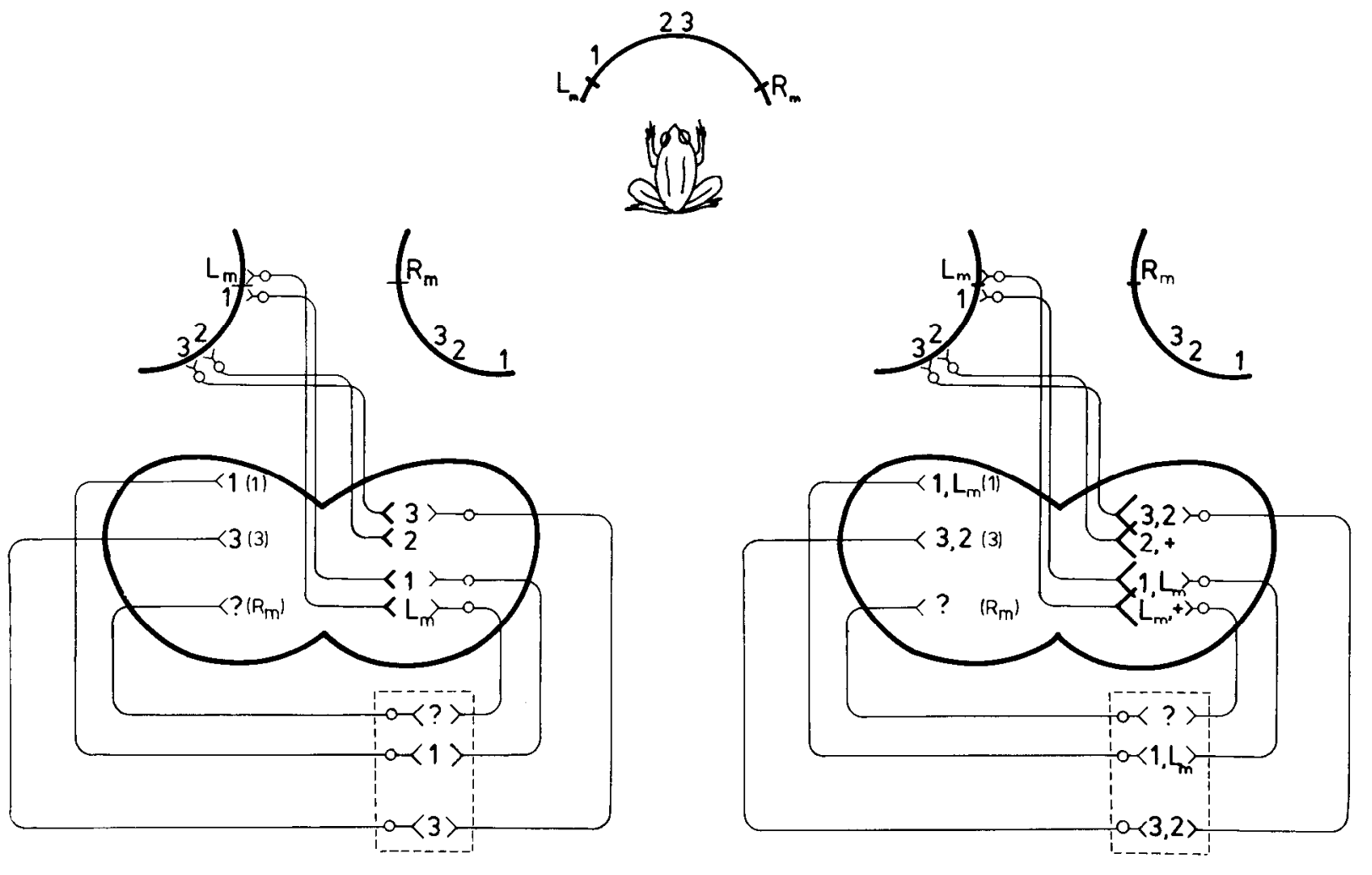

NORMAL

REGENERATING

Figure 1. Schematic illustrations of the organization of the crossed retinotectal and ipsilateral oculotectal projections. To the left side is shown the organization in a normal animal. To the right side is shown the organization during a hypothetical intermediate stage in the recovery of the projections from the left eye following optic nerve crush. In both cases, the organization is characterized in terms of five visual field locations on the horizontal plane, as diagrammed in the upper center of the figure. $L_{m}$ and $R_{m}$ are locations in the monocular fields of the left and right eyes, respectively, close to the edges of binocular field (indicated by short lines). Location 1 is at the left edge of the binocular field; locations 2 and 3 are in the binocular field just to the left and right of the midsagittal plane. The mapping of these points onto the left and right retinae are illustrated in the upper parts of the two diagrams and are identical in the two cases.

The crossed retinotectal projection from the left eye is represented by four retinal ganglion cells corresponding to the four visual field locations within the visual field of that eye. The axons of these cells terminate in an orderly rostrocaudal sequence in the right tectal lobe. A similar retinotectal projection from the right eye is indicated by numbers in parentheses in the left tectal lobe. Fibers from the left eye terminate in the same sequence in both normal and regenerating cases, yielding a similar global topographic order in the two. The terminals in the regenerating case, however, are larger and more overlapping so that the amount of visual field represented at a given tectal locus is larger than in the normal case.

The ipsilateral oculotectal projection from the left eye consists of the crossed retinotectal projection and a topographic intertectal pathway through the nucleus isthmi. The intertectal pathway is represented by tectal cells which project to the nucleus isthmi (boxed region) and nucleus isthmi cells which project to the opposite tectal lobe. For graphic clarity, the intertectal pathway is illustrated for only three of the four locations in the right tectal lobe and a similar intertectal pathway originating in the left tectal lobe has been omitted. Tectoisthmal fibers project in an orderly sequence, with more rostral fibers projecting more ventrally in the nucleus isthmi and more caudal fibers more dorsally. The crossed isthmotectal fibers related to binocular tectum also project in an orderly sequence but with an inversion relative to the afferent projection so that rostral tectum receives input from more dorsally in the nucleus and more caudal binocular tectum from more ventrally. Crossed isthmotectal fibers receiving input from a given locus in the binocular part of the right tectal lobe thus terminate in the binocular part of the left tectal lobe at the same locus as do retinal fibers from the right eye having similarly located receptive fields. The crossed projection to the part of the left tectal lobe representing monocular visual field comes not from ventrally in the nucleus, as would be expected from the orientation of the mapping to binocular tectum, but rather from a dorsal area which also receives the tectoisthmal projection from the right monocular tectum. Activity driven by the left eye is not normally recorded in the left monocular tectum, apparently because the relay through the dorsal part of the nucleus is different from that through the rest of the nucleus. The lack of an effective relay is denoted by a question mark.

The organization of the intertectal relay is shown as identical in the normal and regenerating cases. However, if the larger retinal terminals in the regenerating case form functional synapses, individual tectoisthmal and crossed isthmotectal fibers would, as shown, have larger than normal receptive fields. Hence there would be more than the normal amount of the visual field of the left eye represented at given locations not only in the right tectal lobe but in the left tectal lobe as well. One would also expect, as illustrated, the inclusion in the ipsilateral projection of parts of the monocular visual field of the left eye, a region not normally represented in the projection since the relevant retinal fibers normally terminate more caudally. One would not expect to see an ipsilateral projection to the part of the left tectal lobe which represents the monocular visual field of the right eye, since the absence of such a projection is due to the organization of the nucleus isthmi rather than to the distribution of retinal synapses in the right tectal lobe. 
in ranid frogs. Our findings, consistent with work in other organisms including the tree frog Hyla moorei (Humphrey and Beazley, 1982), indicate that important characteristics of the regeneration process can be missed unless consideration is given not only to the location but also to the size of the aggregate receptive fields recorded at given tectal loci. Since there has been no prior description of the normal organization of the projections in Rana which includes a characterization of aggregate or multiunit receptive fields (MURFs), we describe first some relevant aspects of this organization.

Figure 2 shows a typical example of the contralateral and ipsilateral projections observed in a normal frog. MURFs tend to be somewhat elliptical. With our techniques, they have a diameter, measured along the major axis, which varies from about $20^{\circ}$ to a little over $30^{\circ}$. In general, slightly smaller receptive fields were observed at tectal loci representing the frontal visual field and slightly larger receptive fields at loci representing more peripheral visual fields. At tectal loci representing the binocular visual field, receptive fields could be mapped independently through the contralateral and ipsilateral eyes. In general, these receptive fields overlapped in visual space and were of similar size. An interesting exception to the rule occurs at the caudolateral limits of the part of the tectum representing the binocular field. At these loci the ipsilateral fields tended to be unusually small.

The advantage of analyzing projections in terms of MURFs is that such analysis provides an indication of the precision of the mapping, of how much visual space (or retina) is represented at a given tectal locus, and, conversely, of how widespread in tectum are the projections from a given retinal locus. As illustrated in Figure 1, maps can have quite different degrees of precision and appear similarly ordered topographically if receptive field centers alone are considered. MURF size is, however, a function not only of map precision but also of the size of the tectal area from which signals are recorded. Observations like those in Figure 2 therefore cannot be taken as an invariant measure of map precision. They can, however, be used as a base line against which to measure the precision in experimental cases, so long as one can be certain that changes in the tectal area recorded from are not a confounding variable. Such changes might arise from variations in the electrodes themselves or from changes in the properties of the tectal tissue. MURF sizes like those in Figure 2 were seen in six other normal animals as well as in experimental animals when projections were mapped through the undisturbed eye. As discussed below, this provides evidence that the tectal area recorded from, although unknown, was reasonably constant.

Two further characteristics of the normal ipsilateral oculotectal projection are also of significance in the present study. As illustrated in Figures 1 and 2, the monocular visual field of one eye, which is represented in the caudolateral part of the opposite tectal lobe, is not included in the ipsilateral projection from that eye. In addition, as also illustrated in the figures, there is no ipsilateral projection to the caudolateral tectal region which represents the monocular visual field of the opposite eye. Hence, caudolateral tectum is neither an effective input to nor a target of intertectal circuitry of the kind which links the remaining tectal regions. This seems to be a consequence of the intrinsic organization of the nucleus isthmi rather than of the absence of afferent projections from or efferent projections to caudolateral tectum. The tectoisthmal projection is a continuous and topographic projection coming from all tectal regions (Khalil and Lázár, 1977; Gruberg and Udin, 1978; Grobstein and Comer, 1983). The crossed isthmotectal projection similarly goes to the entire tectal lobe (Grobstein et al., 1978, Gruberg and Udin, 1978). However, the crossed projection is

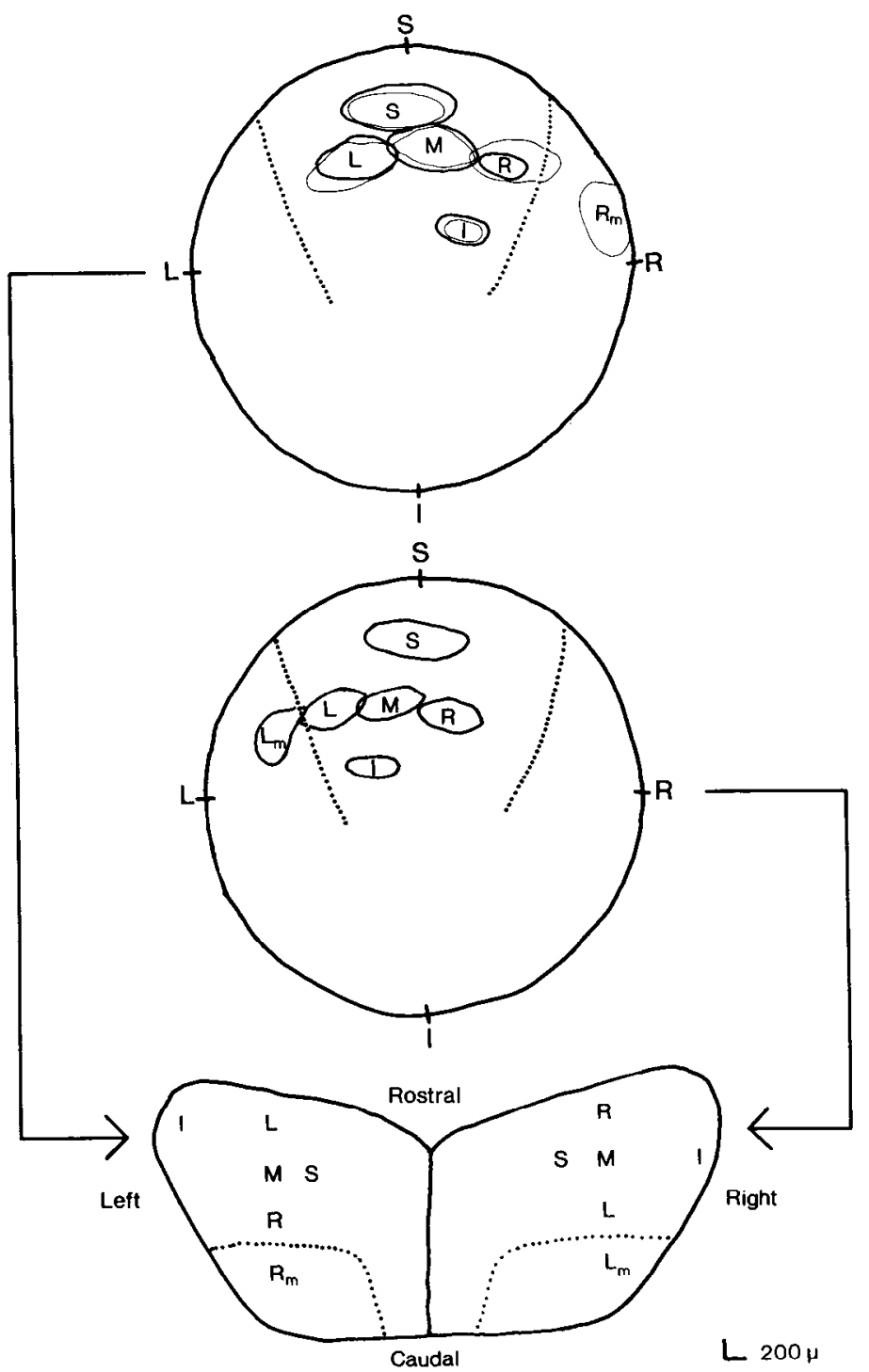

Figure 2. Representative MURFs recorded in the right and left tectal lobes of a normal frog. Circles represent the rostral visual hemifield ( $S$, superior; $I$, inferior; $L$, left; $R$, right); dotted lines show the edges of the binocular visual field. The lower circle shows fields recorded in the right tectal lobe when the left eye alone was activated and hence illustrates the organization of the crossed retinotectal projection from the left eye. Visual fields located to the right of the midline $(R)$, near the midline $(M)$, to the left of the midline $(L)$, and in the left monocular field $\left(L_{m}\right)$, as well as more inferiorly $(I)$ and more superiorly $(S)$ are included. The locations in the right tectal lobe at which these fields were recorded are shown by corresponding letters in the dorsal view of the tectum (bottom). The upper circle shows a similarly identified set of receptive fields recorded in the left tectal lobe. Fields outlined with thinner lines were recorded when the right eye alone was activated; these represent the crossed retinotectal projection from the right eye. Notice that the mapping of visual space in the left tectal lobe is left-right inverted with respect to that in the right. The left monocular field is not represented in the left tectal lobe; the right monocular field $\left(R_{m}\right)$ is represented caudally. Fields outlined with thicker lines were recorded when the left eye alone was activated; these represent the ipsilateral oculotectal projection from the left eye. Notice that the receptive field sizes and topographic organization are like those of the retinotectal projection from the right eye except that there was no ipsilaterally evoked activity at the tectal locus representing a location in the right monocular field. A similar projection from the right eye to the right tectal lobe is not illustrated. 
topographically discontinuous across the border between regions representing the binocular and monocular field (Grobstein and Comer, 1983), so that the cells of origin of the crossed projection to monocular tectum are located not ventrally but dorsally, in an area which also receives tectoisthmal afferents from caudolateral tectum (Grobstein and Masino, 1983; see Fig. 1). The relay through this dorsal part of the nucleus is for some unknown reason less effective than that through the remainder of the nucleus, accounting both for the absence of a monocular visual field representation in the ipsilateral projection from one eye and for the absence of an ipsilateral projection to the tectal region representing the monocular field of the other eye.

\section{The early period of map recovery}

A total of 93 successful recording sessions were made on 81 frogs (several being mapped more than once). Our observations on the general course of map recovery are summarized in Figure 3 . In the vast majority of recording sessions done more than 20 days after optic nerve crush, both the contralateral and ipsilateral projections were present and topographically organized, in the sense that activity could be elicited at all expected tectal loci and there were orderly shifts in receptive field location with shifts in the recording site. The majority of these maps, although topographically organized, were not normal. As detailed in the next section, MURF sizes in both projections were greatly enlarged at earlier times and subsequently declined to normal levels.

Prior to 20 days after optic nerve crush, several kinds of projections with less topographic order were observed. In one group (Blind, in Fig. 3) there was no detectable input from the experimental eye to either tectal lobe; normal input from the undisturbed eye to both tectal lobes was present, indicating that the absence of input was not attributable to poor condition of the preparations. In a second group of frogs (Non-topographic, in Fig. 3) there was observable input from the experimental eye to the contralateral tectal lobe, but none to the ipsilateral. The contralateral projections in these cases lacked apparent topographic order. Activity could be elicited at some but not all tectal loci sampled. At any given locus the visually evoked activity consisted of a small number of units, often having widely dispersed receptive fields. There was no predictable shift of receptive fields for different recording sites. Instead, activity at all tectal loci tended to be driven from a single region of visual space, the area around the projection of the optic nerve head. An example of such a "non-topographic" projection is given in Figure 4 . In these animals, too, the observations cannot be attributed to poor health since projections from the undisturbed eye were normal.

In a third group of animals, topographically organized projections with enlarged multiunit fields were observed over part of the contralateral tectal lobe whereas scattered receptive fields or no input were observed at other points (Partially topographic, in Fig. 3). In five of six such cases, an ipsilateral projection was also observed. Ipsilateral activity was elicitable at tectal loci related to the same areas of visual field as those displaying topographic organization in the contralateral tectal lobe. MURFs at these ipsilateral loci were similarly enlarged. In the sixth animal with enlarged contralateral MURFs, no ipsilateral projection was observed. In a single additional animal the converse was seen: a small area of topographically organized activity in the ipsilateral tectal lobe in the absence of observed topographic organization in the contralateral.

These observations suggest that early map recovery involves an initial phase in which afferents from a small area of the retina project widely across the opposite tectal lobe followed by a restoration of gross topographic order as afferents represent-

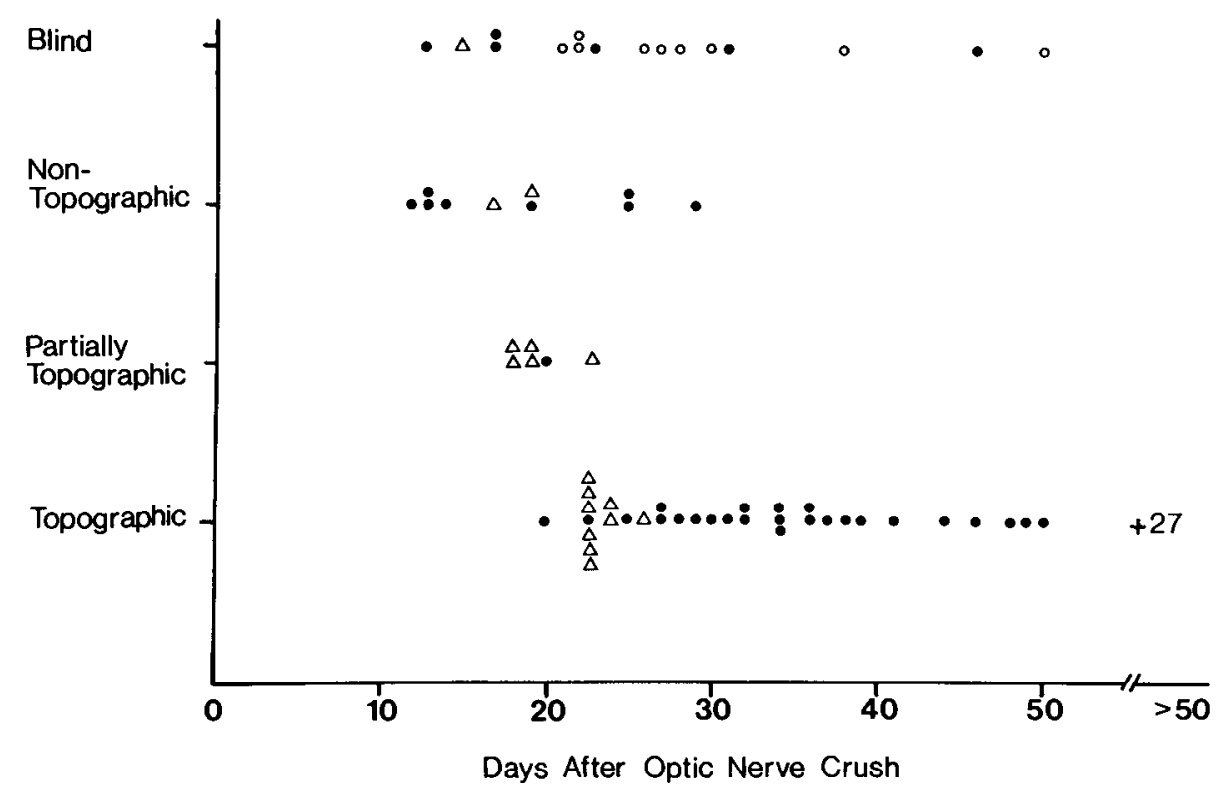

Figure 3. Summary of observations on the recovery of the projections from one eye after optic nerve crush. Each symbol represents one recording session made at a time after optic nerve crush as indicated on the abscissa. The ordinate shows the degree of order in the observed projections in terms of a recovery sequence discussed in the text. When all animals are considered, there is significant overlap in the times after crush at which the various degrees of order were seen. The overlap is reduced if animals recorded from during the winter months (open circles) are not considered. It is reduced still further if attention is restricted to a group of animals all of which received optic nerve crush in the spring of one year (triangles). Each of 27 recording sessions done at more than 50 days after optic nerve crush yielded topographic projections, as denoted to the right. 

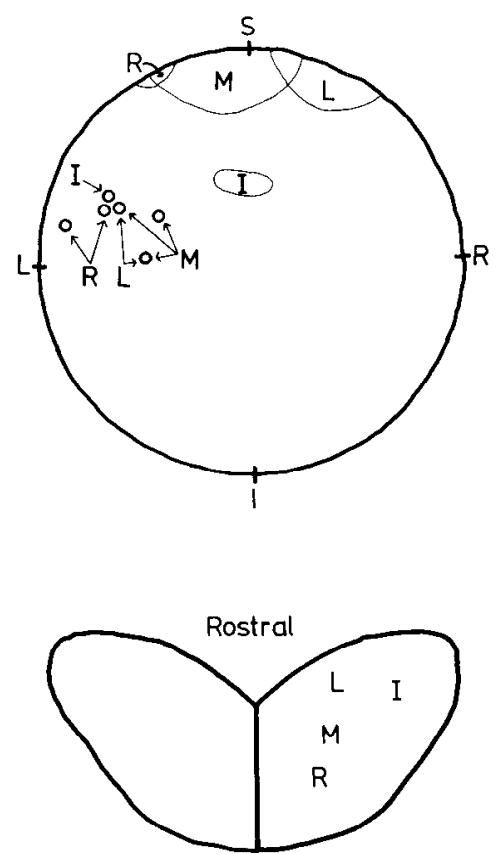

$$
\text { Caudal L } 200
$$

Figure 4. Representative receptive fields from a recording session which yielded a nontopographic or "scattered" retinotectal projection. Illustrated are recordings made in the right tectal lobe, contralateral to the crushed left optic nerve. The ipsilateral projection from the undisturbed right eye to the right tectal lobe was normally organized. This projection, not shown in Figure 2, is represented by the four superiorly located, topographically distributed receptive fields defined by thinner lines. Letters indicate the four recording sites as in Figure 2. The locations in visual space where activity could be driven by the left (experimental) eye at these four recording points is indicated by small circles. Notice that these locations clustered in one area of the visual field and that activity driven from the same location could be recorded at widely dispersed tectal loci.

ing wider areas of the retina return to the tectum. Early phases of this process are not apparent in the ipsilateral projection which instead first appeared as a topographic projection coincident with the appearance of gross topographic order in the contralateral projection. Although map recovery in the sequence from blind through non-topographic and partially topographic to topographic is consistent with the times after optic nerve crush at which various results were obtained, there was, as shown in Figure 3, substantial overlap of these times. Blind animals, for example, were seen as late as 50 days after optic nerve crush. In reviewing our data, we noticed that the vast majority of animals which remained blind at unusually long times had received optic nerve crushes during the winter months (December to February). This suggests that there may be significant seasonal variation in the rate of optic nerve regeneration which would contribute to obscuring the normal recovery sequence. Some further evidence for seasonal variation is presented below. Recordings from a series of animals all subjected to optic nerve crush at the same time yielded a more orderly sequence, as is also shown in Figure 3.

Additional supporting evidence for the sequence of early recovery comes from individual animals which were mapped several times. Five animals blind at first mapping between 20 and 30 days after optic nerve section all exhibited grossly topographic maps at a second recording session done 50 to 62 days after optic nerve section. Three animals with scattered maps on first recording ( 25 to 29 days after optic nerve crush) all exhibited grossly topographic maps on second mappings 46 to 196 days after optic nerve crush. One animal was mapped three times. The first mapping session, at 18 days, revealed a predominantly scattered map; activity was observed at 8 of 17 recording loci. A second session 5 days later revealed restored activity across the entire tectum. Twelve of 17 recorded loci had enlarged topographically ordered receptive fields; the remaining 5 showed no topographic order. A third session, at 90 days, revealed a normally ordered topographic map.

\section{Later events in map recovery}

While our observations on the initial events in map recovery suggest that the earliest and most disordered stages in recovery of the contralateral projection generally have no counterpart in the recovery of the ipsilateral projection, our observations on later events strongly indicate that there is, in the recovery of the ipsilateral projection, a progression from less to more order. The character of the initial abnormalities in the ipsilateral projection and the process of recovery both correlated closely with the state of the contralateral projection, as would be expected if abnormally located retinal afferents form functional synapses (see Fig. 1).

Intermediate times. The contralateral projections in frogs recorded from at intermediate times after optic nerve crush were topographically ordered but abnormal in that they displayed greatly enlarged MURF sizes; the same was true of the ipsilateral projections. Examples are shown in Figures 5 and 6. Enlarged receptive fields were seen at all tectal locations but tended to be most prominent for more caudal loci in the contralateral tectal lobe and, as would be expected from the organization of the intertectal relay (Fig. 1), for more rostral loci in the ipsilateral tectal lobe. In extreme cases (Fig. 5), the enlargement in both projections was great enough so that it would be difficult to establish the existence of topographic order from an analysis of receptive field centers. The borders of the receptive fields, however, clearly shifted in appropriate directions with shifts in recording locus. In extreme as well as less extreme cases (Fig. 6), there was a tendency for field enlargement to be more prominent along one axis than another, resulting in an exaggeration of elliptical shapes. The long axis tended to be similarly oriented at visually corresponding points in the two tectal lobes. It also tended to be similar for a set of nearby recording loci in one tectal lobe, resulting in more receptive field overlap along one tectal axis than the other. Characterization of topographic organization using receptive field centers might in such cases suggest order along one axis and not the other.

The largest MURFs in both the contralateral and ipsilateral projections were seen in animals recorded from relatively earlier after optic nerve crush. The histograms in Figure 7 show the distribution of receptive field sizes in seven normal animals and in eight animals recorded from relatively soon after optic nerve section. Although the scatter of receptive field sizes is greater in the regenerating animals, it is obvious there is roughly a 2 -fold increase in the receptive field size both contralaterally and ipsilaterally. MURF sizes were enlarged not only relative to those seen in normal animals but also, at recording sites where the observations could be made, enlarged relative to simultaneously recorded fields mapped through the undisturbed eye. Such a comparison could be made at all loci in the parts of tectum representing the binocular field, where there are convergent inputs from the two eyes. The relevant data from Figure 7 are redisplayed in Figure 8 in terms of the ratio of simultaneously recorded receptive field sizes. In normal animals, the ratios cluster around 1.0; there is a small tail on the distribution which results from recordings at the edge of binocular tectum where ipsilateral receptive fields tend to be abnormally small. It is evident that fields observed in regenerating animals are not only absolutely larger but larger relative 
to simultaneously recorded fields associated with the normal eye. This indicates that the enlarged receptive fields are not an artifact of changes in the effective recording radius of our microelectrodes due, for example, to changes in tectal tissue resulting from optic nerve section.

Many of the animals with greatly enlarged MURFs also exhibited a second abnormality in their ipsilateral maps, the inclusion in some of the receptive fields of areas of visual space

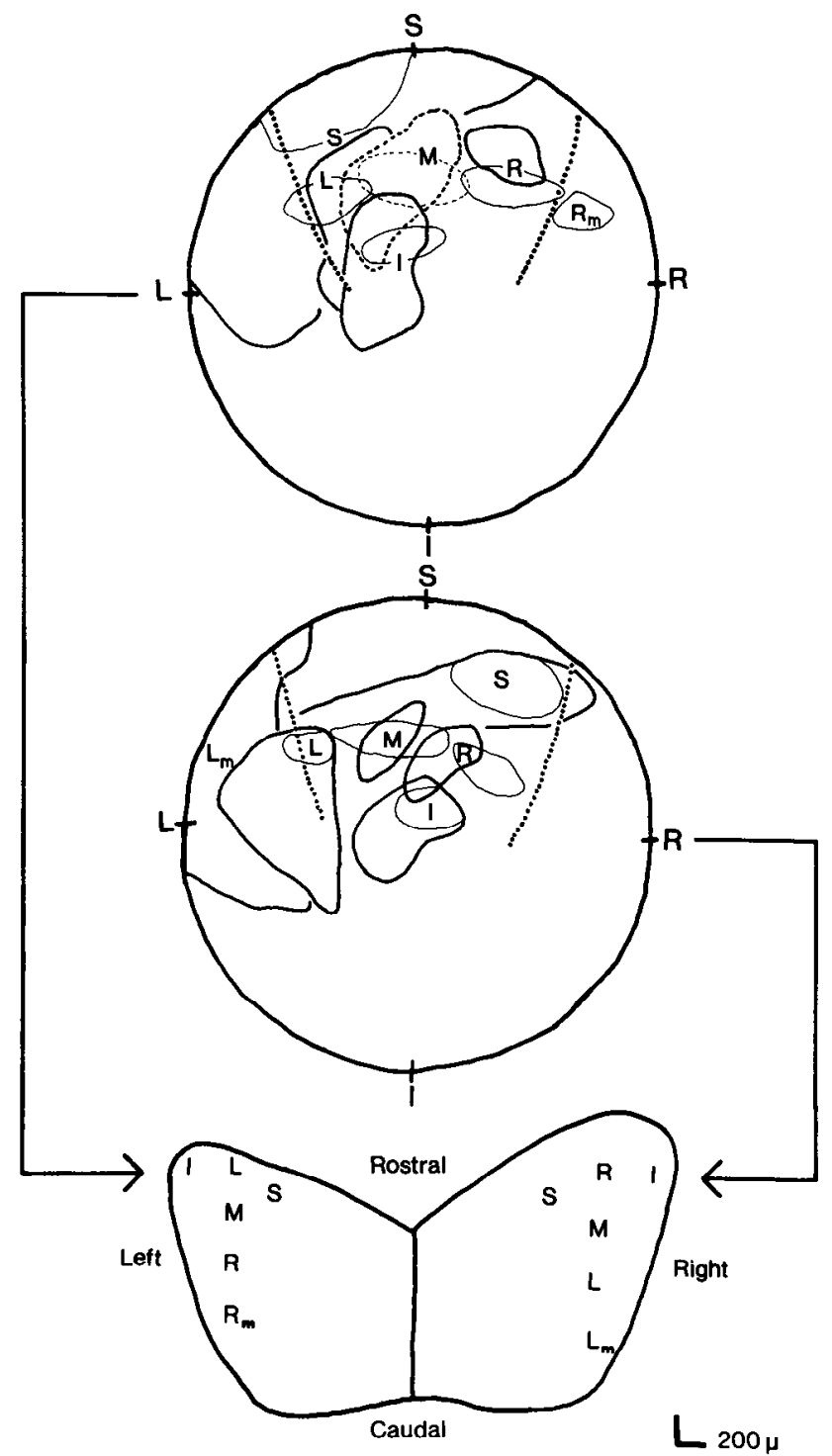

Figure 5. Representative receptive fields from a recording session which yielded topographic projections with greatly enlarged receptive fields. The fields and the tectal locations at which they were recorded are shown as in Figures 2 and 3, except that for both tectal lobes the projections from both eyes are illustrated. Receptive fields mapped through the left, regenerating, eye are shown with thicker lines; those mapped through the right, undisturbed, eye are shown with thinner lines. The letter indicating tectal recording locus is placed within the region of overlap of the receptive fields of the two eyes when two receptive fields were present. Some left eye field borders $\left(L_{m}\right.$ and $S$ for the right tectal lobe; $S$ and $L$ for the left tectal lobe) are obscured by other fields in the visual field maps. Notice that the left eye field recorded at the binocular position $L$ in the right tectal lobe includes some of the left monocular visual field as does the left eye field recorded at $S$ in the left tectal lobe. The latter field is very large; the border extends from above the animal and to the right all the way to the horizontal on the left. Notice also that fields driven through the ipsilateral eye were absent at both $L_{m}$ and $R_{m}$. not normally represented in the ipsilateral projection. As diagrammed in Figure 1, such an abnormality is to be expected if retinal fibers which normally synapse in caudolateral tectum, which is not effectively linked to the opposite tectal lobe, make abnormally located, functional synapses in more rostral tectum. Examples of maps in which ipsilateral MURFs included areas of monocular visual field are illustrated in Figures 5 and 12.

Although the ipsilateral projection during intermediate stages of regeneration was clearly abnormal with regard to both MURF size and the amount of visual field represented, the projection was largely normal with respect to the distribution of tectal loci at which it could be recorded. In normal animals, activity driven from the ipsilateral eye is not recorded in the caudolateral tectal region, which represents the monocular visual field of the contralateral eye (see Fig. 1). In the vast majority of regenerating animals, ipsilaterally driven activity continued to be absent at tectal loci which represent the contralateral monocular visual field, as judged from the MURF location of activity driven by the undisturbed eye (cf. Fig. 5). This observation, too, is consistent with expectations based on the assumption that the organization of the ipsilateral projection reflects synapse formation by retinal fibers in the opposite tectal lobe (Fig. 1). Since the absence of activity in normal animals reflects the organization of the relay through the nucleus isthmi, it should be unaffected by abnormalities in the distribution of retinal inputs to the intertectal relay and altered only if there are changes in the organization of the relay itself. In a minority of animals and small number of penetrations, a few scattered units were visually excitable in the ipsilateral monocular tectum. Such units behaved like those sometimes seen in experiments involving lesions of the contralateral tectal lobe, and we suspect that they were misregenerated optic nerve fibers (see below).

Longer times. Both contralateral and ipsilateral MURF sizes declined with increased time after optic nerve crush, as documented in Figure 9. Fach point in the figure corresponds to a field size ratio for a similar tectal locus (one representing a point in space in front of and slightly above the animal) in one recording session. These ratios are for the most part abnormally large until 60 or so days after optic nerve crush, after which they generally fall within the normal range. A similar decline in receptive field size with time was seen throughout the tectum. Whereas the vast majority of observations support the hypothesis of a progressive shrinkage of MURF sizes, abnormally large fields were seen in a few animals at recording times more than 100 days after optic nerve crush. These animals, like those which were found to be blind after abnormally long periods, were in the process of optic nerve regeneration during the winter months, again suggesting a seasonal effect on the rate of optic nerve regeneration. In six cases of second mappings on the same frog after a first mapping showed enlarged receptive fields, there were subsequent substantial reductions in MURF size. In three other cases, all in the winter, reductions were not observed.

As illustrated in Figure 9, the general time course of decline in MURF sizes in the ipsilateral tectal lobe closely paralleled that in the contralateral tectal lobe, as would be expected if the amount of visual field represented at a given point in the ipsilateral lobe was, throughout the recovery process, a reflection of effective synaptic input by the retinal fibers at a corresponding point in the opposite tectal lobe. To test this more rigorously, we directly compared the sizes of MURFs at given points in the ipsilateral tectal lobe with those at the visually corresponding points in the contralateral tectal lobe. The comparison was made for all possible pairs of points in all of the maps obtained during intermediate and late stages of recovery and is illustrated in Figure 10. It is clear that throughout the regeneration process there was a quite high degree of correlation 


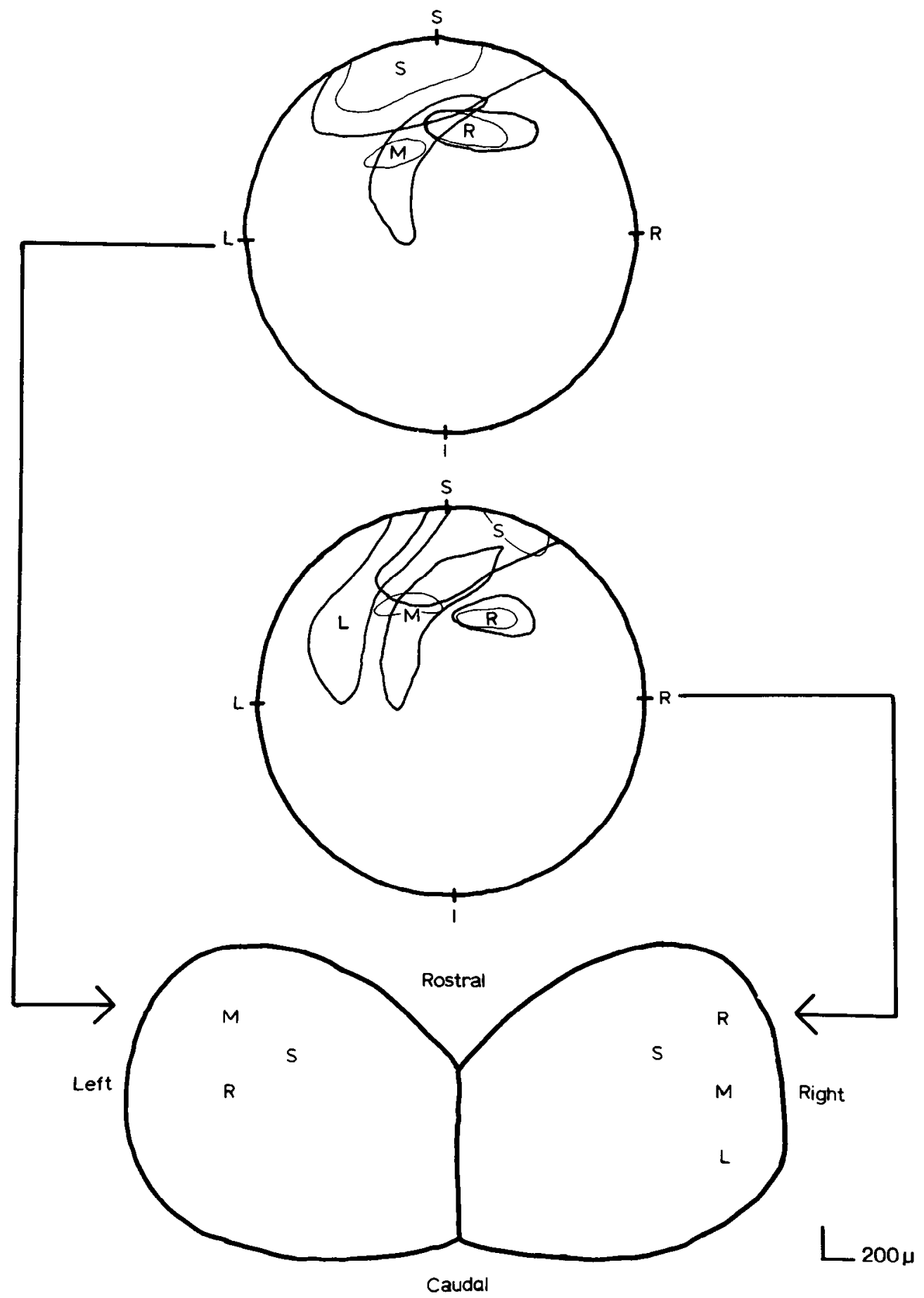

Figure 6. Representative receptive fields from a recording session which yielded topographic projections with moderately enlarged receptive fields. Conventions are as in Figure 5.

between the amount of receptive field represented at visually corresponding points in the two tectal lobes.

\section{Interpretation of enlarged MURFs}

The multiunit observations described clearly indicate that recovery of the ipsilateral projection, like that of the contralateral, involves an initial disordered phase. The observations are also consistent with the interpretation, illustrated in Figure 1, that the disorganization reflects formation by retinal afferents of functional synapses at abnormal locations in the opposite tectal lobe. There are, however, some alternative interpretations of the enlarged MURFs which need to be considered.

Enlarged MURFs in both tectal lobes could be present with no abnormalities either in the distribution of retinal afferent terminals or in synapse formation if changes either in the optics of the eye or in retinal organization produced large increases in the receptive field size of individual retinal ganglion cells. To evaluate this possibility we measured the receptive fields of a number of single units isolated from the multiunit activity giving enlarged MURFs and compared these to single unit receptive field sizes observed in normal animals. The 
distributions of field sizes for contralateral units in the two cases were essentially indistinguishable (Fig. 11), indicating that the explanation of enlarged MURFs does not pertain to either optical or retinal abnormalities. In contrast to the normalcy of contralateral single unit receptive field sizes, single units isolated from the enlarged ipsilateral MURFs clearly had abnormally large fields (Fig. 11). This is to be expected if enlarged ipsilateral MURF size is due to unusually wide convergence of retinal input onto single channels of the intertectal pathway (see Fig. 1).

While our evidence strongly implies disorganized retinal projections as the basis of enlarged visual field representations at single loci in the contralateral tectal lobe, there are explanations of the enlarged visual field representations in the ipsilateral tectal lobe other than formation of functional synapses by the abnormally located retinal fibers. One is the possibility of visual information reaching the ipsilateral tectal lobe by some unusual route; there is, for example, evidence for an aberrant direct ipsilateral retinal projection during optic nerve regeneration (Gaze and Jacobson, 1963; Gaze and Keating, 1970a, b; Kicliter et al., 1974; Glastonbury and Straznicky,
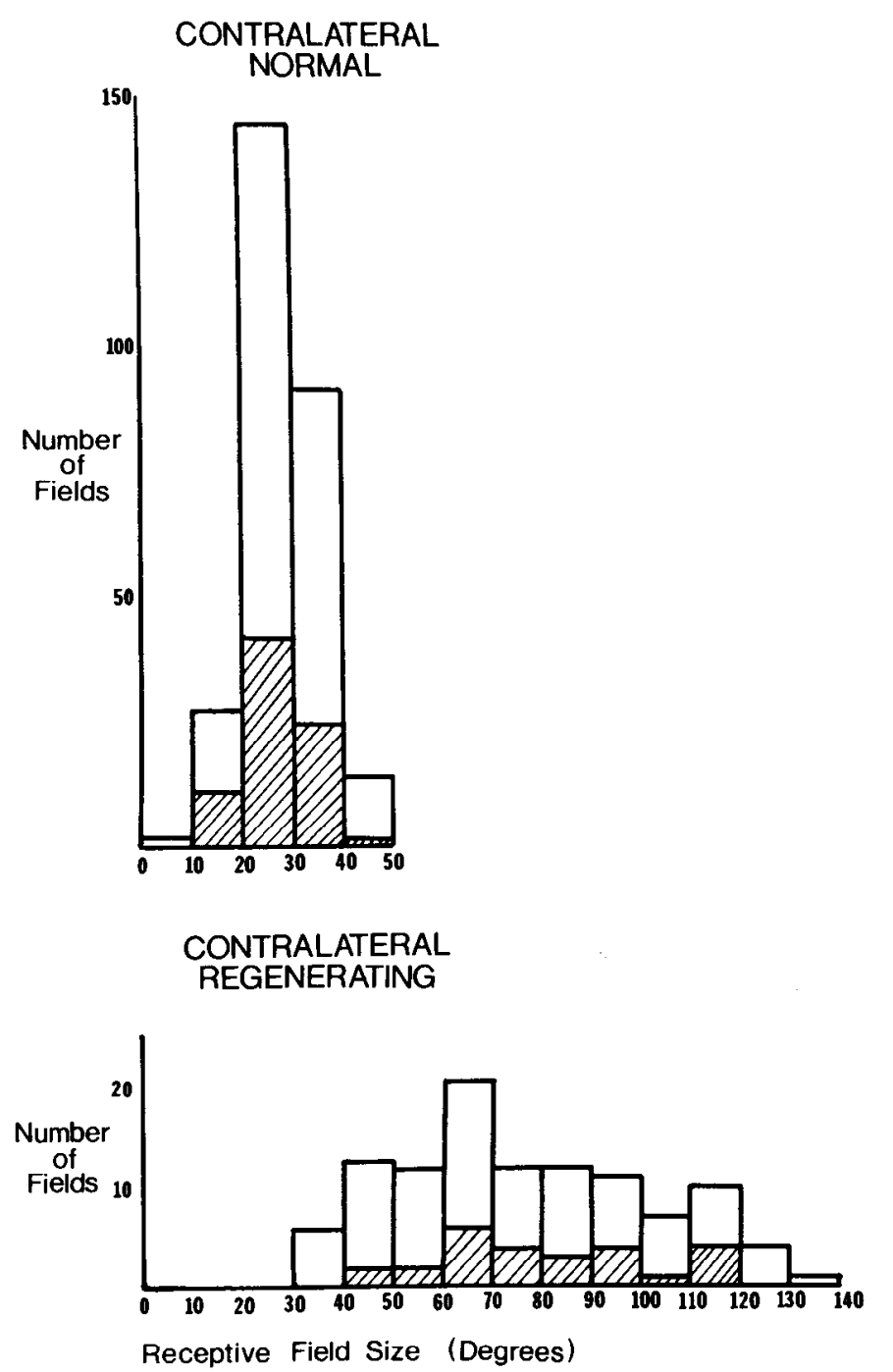

1978). A second possibility is that optic nerve section produces abnormalities in the intertectal pathway and that it is these rather than abnormal synapse formation by retinal terminals that result in the enlarged receptive fields.

To evaluate these possibilities we performed experiments like those illustrated in Figure 12 in which the dependence of ipsilateral activity on the contralateral tectal lobe was evaluated by making small electrolytic lesions in that tectal lobe. Similar experiments were done in six other frogs. In all cases the abnormally enlarged ipsilateral fields were abolished by lesions at the corresponding point in the contralateral tectal lobe, while enlarged receptive fields remained present at loci $300 \mu \mathrm{m}$ or less away. Although the enlarged receptive fields were always abolished, in four of the cases some ipsilaterally evoked activity remained in the form of one to several single units with small receptive fields. The residual units, unlike normal ipsilateral units, did not habituate to repeated stimulation but instead continued to respond reliably, as do contralateral units. We suspect that they, like the occasional ipsilaterally driven units seen in monocular tectum, represent a small population of retinal afferents which projected to the wrong tectal lobe during

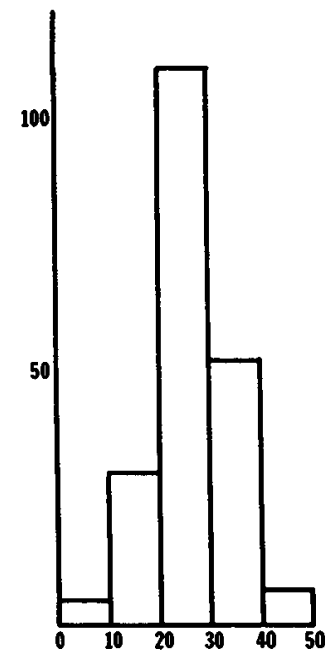

IPSILATERAL REGENERATING

Figure 7. Distributions of contralateral and ipsilateral MURF sizes in normal and regenerating animals. The upper histograms show for seven normal frogs the number of fields observed (ordinate) which had sizes in the ranges indicated on the abscissa. Measurements represent degrees of visual angle across the longest axis of the field. The lower histograms show the same distributions for regenerating projections in eight animals during intermediate stages of regeneration, when enlarged MURFs were observed. Shading in the contralateral distribution shows fields in monocular tectum where ipsilateral receptive fields could not be recorded simultaneously. 

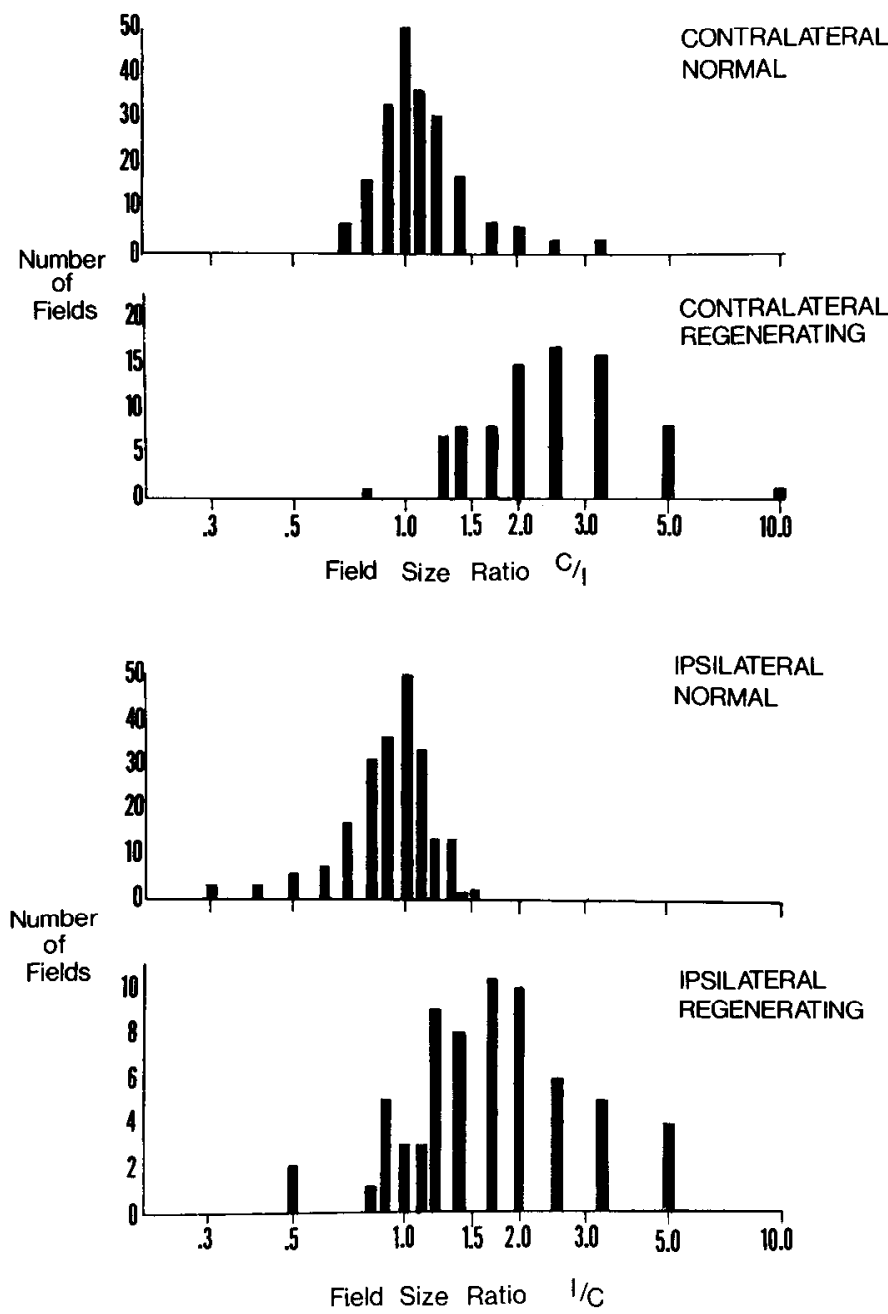

Figure 8. Comparisons of the sizes of the two MURFs, one related to each eye, which were recorded at single tectal loci in normal and regenerating animals. The figure is based on the same observations as those illustrated in Figure 7, except that recording locations in monocular tectum, where activity could be driven only through one eye, are excluded. For each locus in binocular tectum a ratio of the receptive field sizes as mapped through the eyes contralateral and ipsilateral to the recording location was determined. The histograms show the number of recording locations (ordinate) at which these ratios fell within the values indicated on the abscissa (notice that the scale is logarithmic). The top histogram shows the contralateral to ipsilateral ratio for normal animals. The second histogram shows the contralateral (experimental eye) to ipsilateral (normal eye) ratios for recordings in the tectal lobe opposite the crushed optic nerve in regenerating animals. The third histogram shows the ipsilateral to contralateral ratios for normal animals. The bottom histogram shows the ipsilateral (experimental eye) to contralateral (normal eye) ratios for recording points in the tectal lobe on the same side as the crushed optic nerve in regenerating animals.

regeneration. Regardless, the results indicate that the enlarged ipsilateral receptive fields, like normal receptive fields, are dependent on the integrity of the contralateral tectal lobe and hence are likely to be a reflection of activity carried over the normal intertectal relay.

Our lesion results also bear on the question of whether there are gross abnormalities in the intertectal relay which could account for the enlarged ipsilateral receptive fields. Enlarged ipsilateral fields might be seen with normal selectivity in ganglion cell synapses if optic nerve section created abnormalities in the intertectal pathway such that wider than normal areas of tectum were represented on individual channels of the inter- tectal relay. Were this the case, however, one would expect local tectal lesions not to abolish activity at a particular locus in the ipsilateral tectal lobe but rather to somewhat alter the activity at a large number of loci. Although it is not possible from our observations to say that optic nerve section had no effect on the organization of the intertectal relay, our observations do indicate that there is, as in normal animals, a substantial topographic precision in the pathway. Together with other results, the lesion findings make it unlikely that it is abnormalities in the intertectal relay which accounts for the enlarged MURFs. This point is considered further under "Discussion."

\section{Discussion}

The present results add to existing information on the character of intermediate stages in the recovery of the direct retinotectal projection in the frog and provide the first description of intermediate stages in the recovery of the ipsilateral oculotectal projection. With regard to the retinotectal projection our findings indicate that there is a rather rapid re-establishment of gross topographic order followed by a longer period during which the normal precision of the mapping is re-established. The re-establishment of the ipsilateral projection closely parallels later stages of recovery of the contralateral projection, suggesting that the process reflects a period of reordering of functional synapses made by terminals of the crossed projection. Our results thus imply that ganglion cell terminals do not display a degree of selectivity in choosing synaptic sites adequate to account for the normal organization of the retinotectal projection.

\section{The direct retinotectal projection}

Electrophysiological studies similar to those reported here were carried out first in the frog (Gaze and Jacobson, 1963) and then in the goldfish (Jacobson and Gaze, 1965) and newt (Cronly-Dillon, 1968). It appeared from the initial reports that there might be substantial species differences in the pattern of recovery of the retinotectal projection. In the goldfish, for example, no evidence for an intermediate disordered stage was observed. It now appears that at least the later phases of regeneration are similar in all three animals. Cronly-Dillon (1968) was the first to pay close attention to MURF sizes and described a progressive shrinkage of these during regeneration in the newt. Evidence for a similar phenomenon in teleosts was obtained by investigators who noted MURF size (Horder, 1971; Schmidt and Edwards, 1982; Northmore and Masino, 1984). Enlarged MURFs imply convergence of wider than normal retinal regions at individual tectal loci and, conversely, divergence from individual retinal loci to wider than normal tectal regions. Anatomical evidence for the latter has been provided by Meyer (1980) in the case of goldfish. Fujisawa et al. (1982) have presented evidence, in the case of the newt, that the widespread projection is probably due to abnormally wide branching of the terminal arbors of individual afferents.

In the case of the frog, the initial electrophysiological studies of regeneration (Gaze and Jacobson, 1963; Gaze and Keating, 1970a) showed widespread projections from restricted retinal regions at early times after optic nerve crush, a pattern probably corresponding to the scattered maps observed in the present study and the "inconstant" projections of Humphrey and Beazley (1982). Between this and a fully reorganized projection, the only intermediate stage described in the initial studies was one characterized as topographically ordered along one but not the other axis. More recently, Humphrey and Beazley (1982) have described in Hyla a sequence of rapid re-establishment of gross topographic order followed by a progressive decline of MURF size to normal levels which is virtually identical to our findings in Rana. In discussing their findings in relation to 

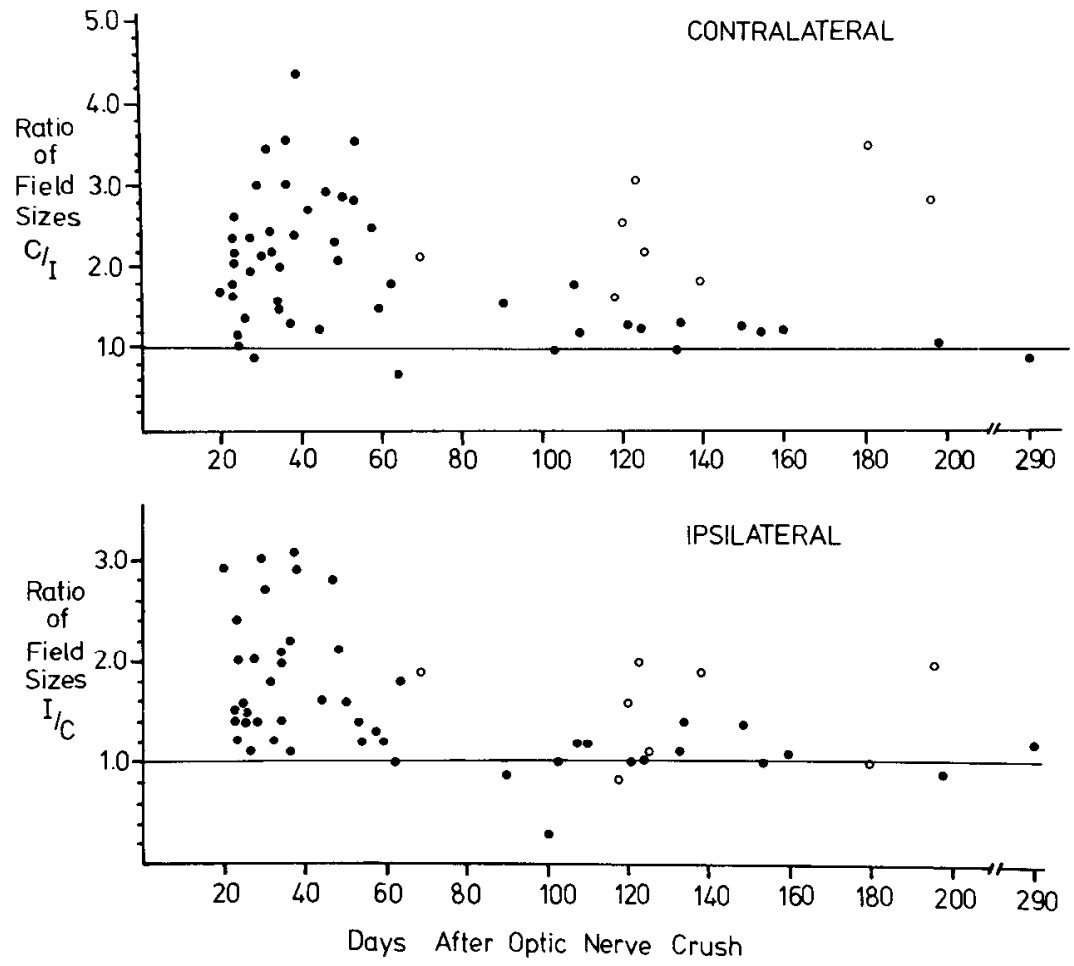

Figure 9. Decline in contralateral and ipsilateral MURF size ratios with time after optic nerve crush. Each point corresponds to one recording session at a time after optic nerve crush as indicated on the abscissa. For each recording session, the ordinate shows the ratio of receptive field sizes observed at a tectal locus representing a point in visual space on the sagittal plane at approximately $60^{\circ}$ elevation. The upper part of the figure shows values for points in the tectal lobe contralateral to the crushed optic nerve and the lower part shows the values in the tectal lobe ipsilateral to the crushed optic nerve. This particular tectal locus was chosen simply to facilitate comparison among animals; the data shown are representative of the time course of recovery throughout the tectum. Open circles indicate recordings made during the winter months, as described in the text.

earlier work, Humphrey and Beazley (1982) suggested that the differences in recovery sequence may relate to different loci of optic nerve crush, outside the skull in their case and inside in the earlier work. Like Humphrey and Beazley (1982) we crushed the optic nerve outside the skull, perhaps accounting for the fact that our description of the recovery sequence is more similar to that in Hyla than to earlier findings in Rana. There is, however, an alternate interpretation of the different descriptions which seems to us also possible. The maps described in the earlier work were largely characterized in terms of receptive field centers. It seems likely that, given the concern at the time with gross topographic order, the phenomenon of progressively decreasing receptive field size may simply have been missed. A focus on receptive field centers might also yield an impression of order along one and not the other axis, given the asymmetric enlargement of receptive fields we observed. Regardless of whether this or the alternate interpretation suggesting a different sequence following intracerebral crush is correct, it seems clear that there is at least one recovery sequence which is seen in all animals investigated and which involves quick establishment of gross topographic order and subsequent decline of MURF size.

The morphological substrate of the enlarged MURFs seen in the frog seems likely to be the same as that suggested by work in the goldfish and newt. The enlarged fields in Rana cannot be attributed to optic or retinal abnormalities given the small single unit receptive field sizes we observed. The small single unit receptive field sizes observed also make it unlikely that enlarged fields result from contamination of our recordings by signals from postsynaptic units, since these typically have much larger receptive fields (Grüsser and Grüsser-Cornehls, 1976). Nor can the enlarged fields be attributed to abnormalities in the amount of tectum recorded from, since simultaneously recorded MURFs mapped through the normal eye were normally sized. This leaves abnormal convergence of afferents from the retina as the most likely explanation for the enlarged fields even leaving aside the correlative evidence from other organisms. Such abnormal convergence would be accounted for if, as in the newt, individual retinal fibers terminate over an unusually wide area. However, it could also be accounted for without unusual branching if the terminals from a group of ganglion cells representing a particular retinal locus are dispersed more widely than normal. Distinguishing between these two possible explanations for abnormal convergence is not possible from our electrophysiological observations and must await anatomical studies in the frog.

\section{The ipsilateral oculotectal projection}

Our findings indicate that the ipsilateral oculotectal projection, like the retinotectal projection, is not directly re-established after optic nerve crush but instead first appears as a somewhat disorganized projection which progressively becomes more ordered with time. Also like the direct projection, the initial disorganized ipsilateral projection is characterized by greatly enlarged MURFs, which cannot be attributed to optical or retinal abnormalities (since they occur at a time when single unit receptive fields in retinal afferents are normal) or to abnormalities in effective electrode recording radius (since 


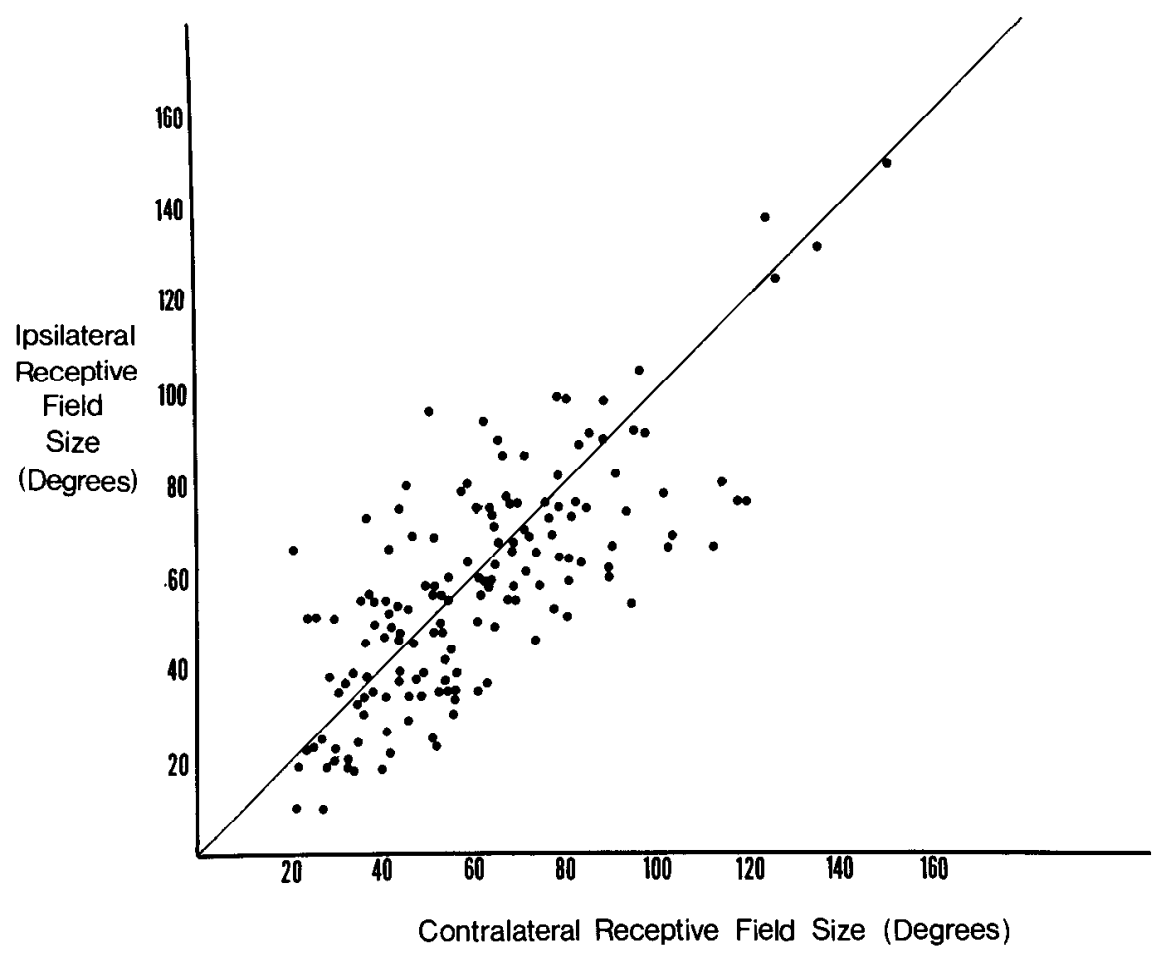

Figure 10. Dependence of MURF size in the tectal lobe ipsilateral to a regenerating optic nerve on that in the contralateral tectal lobe. The size of a given MURF in the ipsilateral tectal lobe is plotted as a function of the size of the MURF recorded at the visually corresponding point in the contralateral tectal lobe of the same animal. All maps with topographically organized projections were examined and all points were included where there was significant overlap of fields in the two tectal lobes as mapped through the undisturbed eye. The line at $45^{\circ}$ represents perfect correspondence of receptive field size in the two tectal lobes.
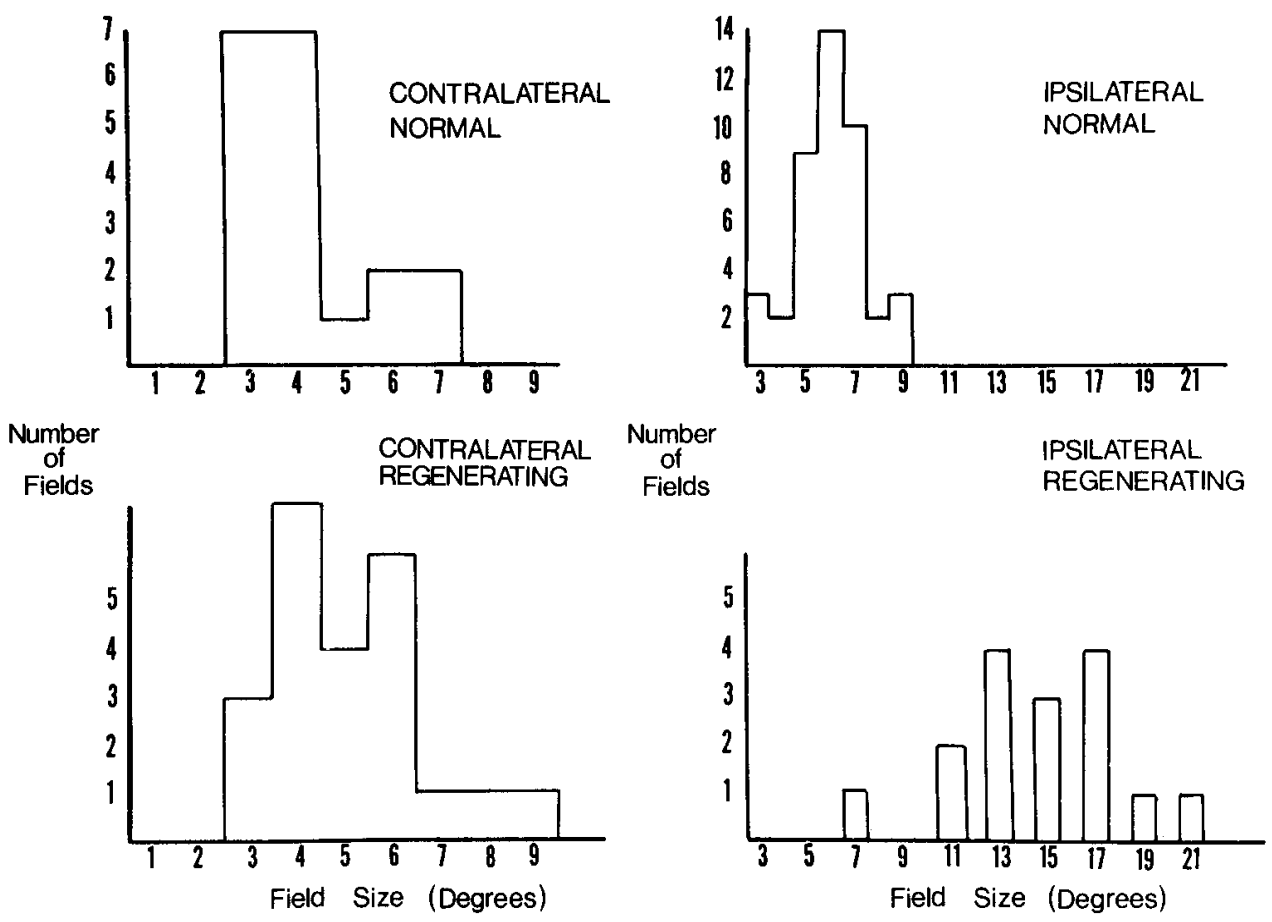

Figure 11. Single unit contralateral and ipsilateral receptive field sizes in normal and regenerating animals. The upper histograms show in normal animals the number of fields observed (ordinate) having sizes indicated on the abscissa. The lower histograms show the same distributions in animals having enlarged MURFs. 


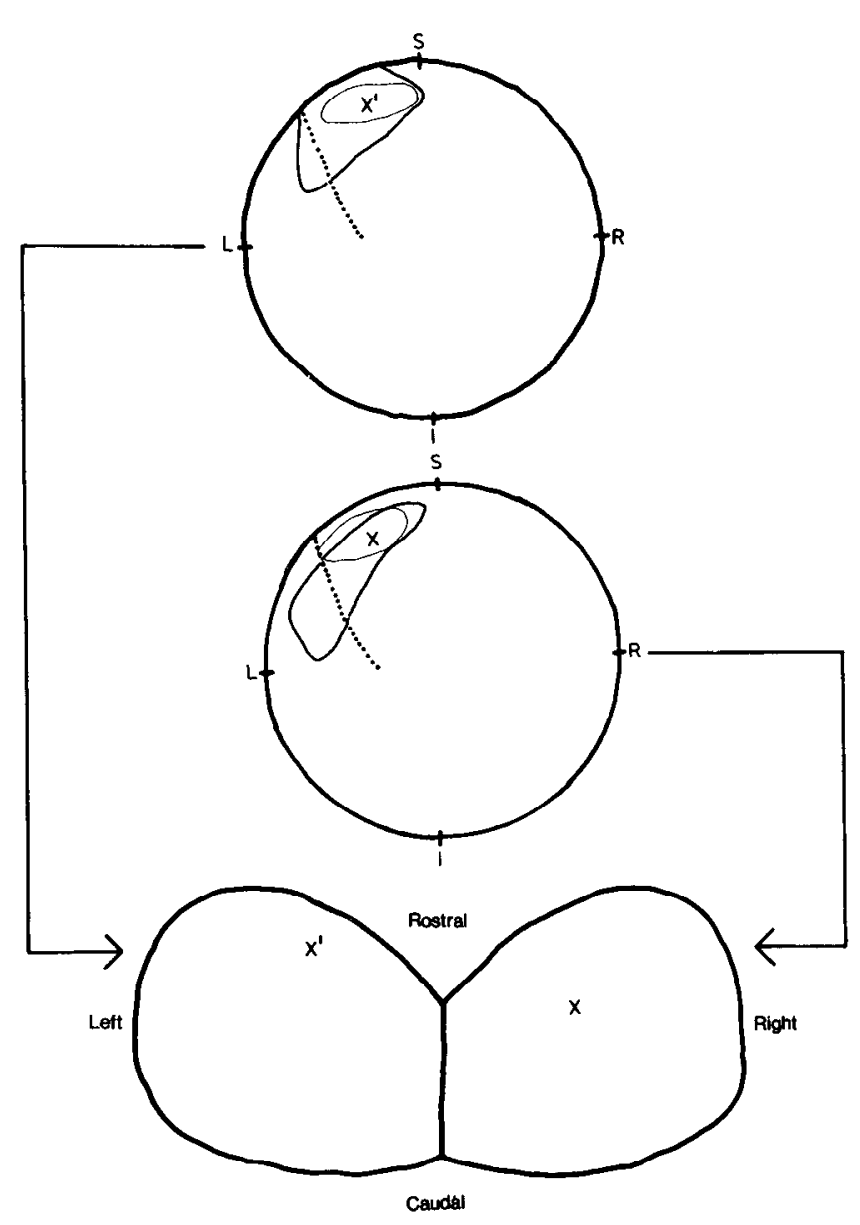

Pre-Lesion

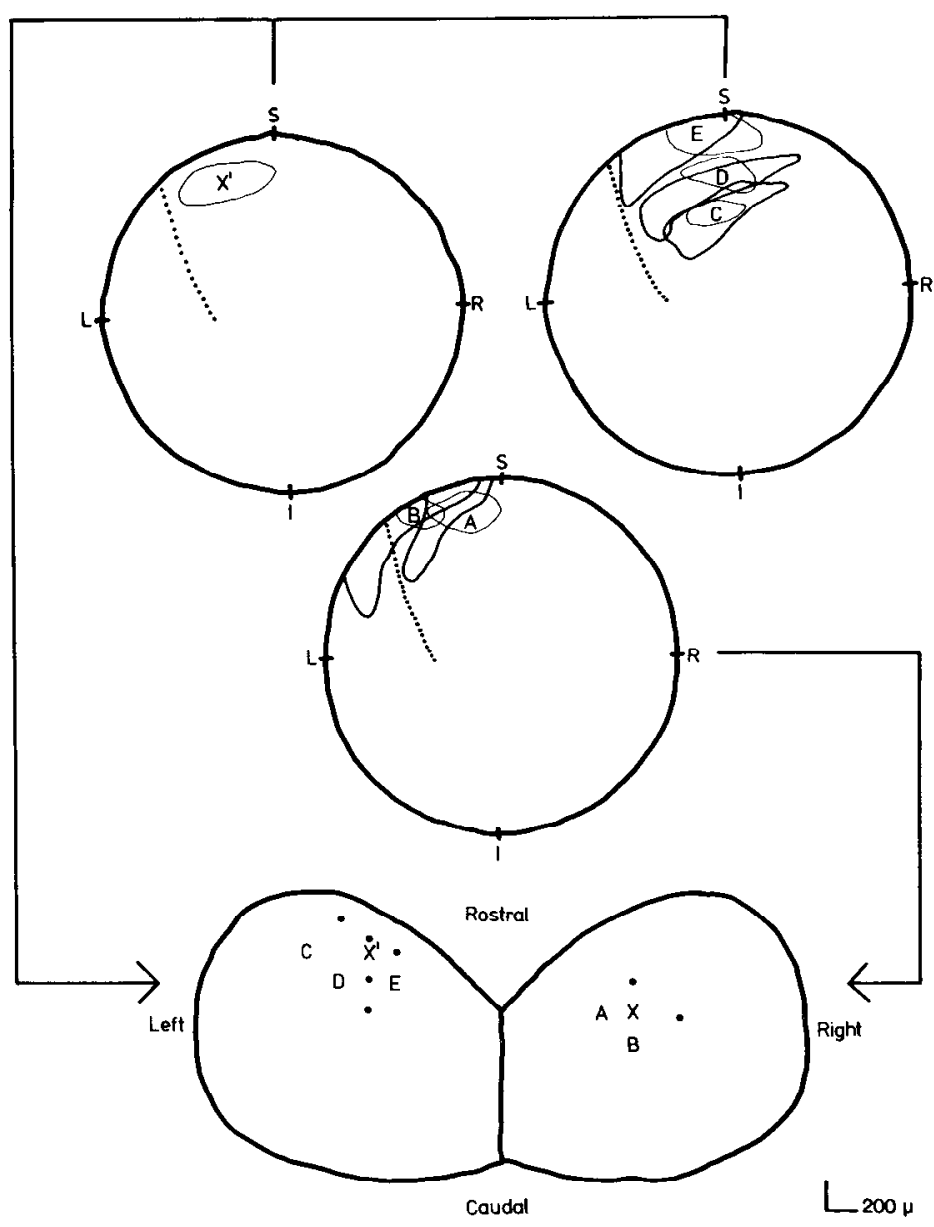

Post-Lesion

Figure 12. Dependence of enlarged ipsilateral MURFs on the integrity of the visually corresponding location in the contralateral tectal lobe. To the left are shown receptive fields recorded at visually corresponding locations in the left and right tectal lobes at an intermediate time after crush of the left optic nerve. Conventions are as in Figures 2, 4, 5, and 6. Notice that the fields mapped through the left eye (thicker outlines) are larger than those through the right and that included are areas of the left monocular visual field. To the right are shown receptive fields in the same animal after an electrolytic lesion at point $X$ in the right tectal lobe. The lesion abolished recordable activity at point $X$ but left activity at adjacent points $A$ and $B$, as illustrated (activity also survived at other nearby points indicated by the dots). The lesion also abolished the ipsilaterally evoked activity at $X^{\prime}$ but did not, as illustrated, abolish contralaterally evoked activity at this point or either of the two forms of activity at adjacent points $C, D$, or $E$, all of which continued to exhibit enlarged ipsilateral MURFs (such fields were also present at other adjacent points as indicated by dots).

simultaneously recorded MURF sizes from the normal eye are normal). Unlike the crossed projection, enlarged MURFs are accompanied by enlargement of the receptive fields of the individual units within the recorded multiunit clusters.

The simplest interpretation of our findings on the recovery of the ipsilateral projection is that mislocated terminals of the crossed projection do in fact form functional synapses. All available evidence indicates that the pathway of the ipsilateral projection consists of the crossed direct retinotectal projection and a subsequent topographic intertectal pathway relaying the effective retinal input from a given tectal locus to a corresponding locus in the opposite tectal lobe. If functional synapses are formed by retinal fibers during the period when afferents coming from wider than normal retinal areas are present at loci in the contralateral tectal lobe, one would expect to find, as we did, abnormally wide areas of retina represented at individual loci in the ipsilateral tectal lobe. Since the abnormal convergence is onto elements of the intertectal relay, one would also expect in the ipsilateral pathway abnormally large single unit receptive fields, a phenomenon we also observed. Finally, one would expect to see areas of visual field represented in the ipsilateral pathway which are not normally represented there. This was also observed.

While the phenomena described are exactly those which would be expected if abnormally located retinal terminals form functional synapses, it is possible that the correspondence to expectation is coincidental and that the enlarged receptive fields in the ipsilateral projection have some other cause. Direct ipsilateral projections from the eye have been reported as a consequence of optic nerve damage, and our own observations indicate that some abnormalities of this kind may have been present. These, though, are unlikely to account for the enlarged receptive fields. The single unit sizes observed in the enlarged MURFs were substantially larger than those which characterize retinal fibers. More importantly, the bulk of the ipsilaterally evoked activity, like that in normal animals, could be abolished by damage to the contralateral tectal lobe. The latter also supports the notion that the activity depended on the intertectal pathway rather than some totally anomalous path such as one through the thalamus. 
A more difficult possibility to exclude is that the abnormalities seen in the ipsilateral pathway do not reflect abnormal synapse formation in the contralateral tectal lobe but rather changes in the intertectal pathway itself. This too seems unlikely. Local damage in one tectal lobe produces loss of ipsilaterally driven activity locally in the other tectal lobe, just as it does in normal animals (Keating and Gaze, 1970). Gross changes in the intertectal pathway might also be expected to result in creation of effective inputs to monocular tectum. We saw no activity suggesting such a change. A third reason for believing the intertectal pathway to be stable is the close correspondence in the sizes of ipsilateral and contralateral MURFs throughout the process of regeneration. There was at all times a close correspondence between the size of a given ipsilateral receptive field and that seen at the visually corresponding point in the opposite tectal lobe. To account for our findings in terms of normal synapse formation and abnormalities in the intertectal pathway requires the assumption of a rather specific series of changes in the intertectal pathway, one which, by coincidence, causes exactly the same sequence of changes in the ipsilateral projection as would be expected to occur given a stable intertectal pathway and abnormal synapse formation. Although we cannot absolutely rule this out, it seems by far the less likely possibility. Our observations on abnormalities in the ipsilateral projection thus strongly imply formation of functional synapses by abnormally located retinal terminals in the contralateral tectal lobe. The subsequent recovery of the ipsilateral projection suggests that recovery of the retinotectal projection involves progressive changes not only in terminal arbor location but in the location of effective synapses as well.

This conclusion is consistent with that reached from observations on tectal cell responses during optic nerve regeneration (Udin, 1975), although the normal variability of such responses made a firm conclusion difficult. The only other observations possibly bearing on the issue of whether abnormally located terminals form effective synapses during regeneration are those on the recovery of orienting behavior. Abnormally located synapses might be expected to result in substantially misdirected orienting responses. A quantitative study to determine whether this prediction holds has not been reported. Sperry (1944) did not mention a phase of substantially misdirected responses prior to the recovery of normal behavior. Maturana (1958), working with the toad, did. We attempted to follow the behavioral recovery of several of the frogs in the present study but had difficulties getting reliable hehavioral results. Our observations did, however, suggest that the onset of consistent orienting responses is delayed relative to the appearance of a grossly topographic retinal projection and of effective synapse formation, as implied by the existence of an ipsilateral projection. Both projections were observed in a number of frogs prior to the time when they began to consistently orient to visual stimuli. Consistent orienting typically appeared rather abruptly. In some frogs the responses, when they appeared, were of normal accuracy; in others, as also observed by Udin (1975), there were small inaccuracies. In general there did not appear to be a good correlation between the presence of effective synaptic input and behavior. A recent quantitative study of optic nerve regeneration in the goldfish (Northmore and Masino, 1984) is also of interest in this regard. Normally directed orienting behavior was observed at stages when MURF size was still enlarged. We did not attempt to determine the state of the projections in the frog at the time orienting reappeared. This might be worth doing, since an independent assay of synaptic input was not available in the goldfish. The finding of normal orienting in the presence of enlarged ipsilateral as well as contralateral fields in the frog would imply that the precision of the retinotectal input is not critical to the precision of orienting behavior.

\section{Implications for understanding the genesis of topographic maps}

The factors responsible for producing topographic ordering of retinotectal afferent terminals have been a subject of extensive study since the original descriptions of its re-establishment during optic nerve regeneration (for reviews see Hunt and Jacobson, 1974; Meyer and Sperry, 1976; Gaze, 1978; Horder and Martin, 1978; Fraser and Hunt, 1980; Hollyday and Grobstein, 1981; Schmidt, 1982). A strong implication drawn from the original studies of optic nerve regeneration was that, given the scrambling of optic axons at the site of damage, topographic order could not be accounted for simply on the assumption of a particular stereotyped spatiotemporal pattern of outgrowth occurring within a population of otherwise undifferentiated axons (Sperry, 1944; see also Fawcett and Gaze, 1981). Rather, it must be the case that the axons differ from one another in their responses to cues encountered during growth in such a way as to yield topographic order. Our findings, like previous ones on regeneration showing that there is a disordered phase in recovery of the retinotectal projection, indicate that such ordering interactions are not completed prior to the arrival of axons in the tectum (see also Udin, 1978). The rapid reestablishment of global topographic order prior to the appearance of more local order, also observed in other studies, suggests that the two aspects of topographic organization may depend on different mechanisms. Consistent with this is recent evidence in the goldfish indicating that global but not local order can be re-established in the absence of impulse activity (Schmidt and Edwards, 1982; Meyer, 1983). Global order could be a consequence of the responses of optic axons to tectal cues, either intrinsic (Sperry, 1963) or induced by previous innervation (Schmidt, 1978). It could also reflect responses to cues earlier in the growth path (Attardi and Sperry, 1963) or interactions between the outgrowing axons themselves (Meyer, 1979). Our only evidence bearing on this issue is the observation that global order seems not to be present until axons representing substantial amounts of the retina have returned to the tectum. This suggests that fiber interactions may play a role in such ordering but by no means rules out the possibility that responses to cues in the growth path and in the tectum do so as well.

Our primary new contribution to understanding topographic ordering is our evidence that neither global nor local order can be attributed to an inability of optic axons to form synapses at other than normal locations. Prior electrophysiological studies of recovery of the retinotectal projection, with the single exception mentioned previously, have, like our own, used recording techniques which favor detection of activity in terminal arbors of retinal afferents rather than in tectal cells. While providing strong evidence for abnormally located terminal arbors at early stages of regeneration, neither they nor available anatomical studies resolved the issue of whether the abnormally located terminals form functional synapses. It thus remained possible, despite the evidence for mislocated terminals, that ganglion cell axons display a very high degree of recognition of tectal sites in terms of synapse formation. A similar ambiguity holds for most other experimental work on the anuran retinotectal system (but see Udin, 1977). Our findings by no means preclude the possibility that tectal targets, like ganglion cells, are differentiated and that some recognition process between the two cell types is involved in producing topographic order in the retinotectal pathways. Other evidence for such a process exists (Jacobson and Levine, 1975; Straznicky, 1978). Our findings do, however, provide the strongest available evidence that such a recognition process, at the synaptic level, is not sufficiently 
specific to preclude patterns of connections other than the normal one. Our findings thus contribute to a developing consensus that normal topographic order in the retinotectal projection is probably not attributable to a single mechanism but instead is the outcome of several distinguishable processes acting together (Hollyday and Grobstein, 1981).

\section{References}

Adamson, J., and P. Grobstein (1982) Re-establishment of the ipsilateral oculotectal projection after nerve crush in the frog: Fvidence for synaptic remodeling during regeneration. Soc. Neurosci. Abstr. 8: 514.

Attardi, D. G., and R. W. Sperry (1963) Preferential selection of central pathways by regenerating optic nerve fibers. Exp. Neurol. 7: 46-64.

Cronly-Dillon, J. (1968) Pattern of retinotectal connections after retinal regeneration. J. Neurophysiol. 31: 410-418.

Fawcett, J. W., and R. M. Gaze (1981) The organization of regenerating axons in the Xenopus optic nerve. Brain Res. 229: 487-490.

Fraser, S. E., and R. K. Hunt (1980) Retinotectal speciticity. Annu. Rev. Neurosci. 3: 319-352.

Fujisawa, H., N. Tani, K. Watanabe, and Y. Ibata (1982) Branching of regenerating retinal axons and preferential selection of appropriate branches for specific neuronal connections in the newt. Dev. Biol. 90: $43-57$.

Gaze, R. M. (1978) The problem of specificity in the formation of nerve connections. In Specificity of Embryological Interactions, D. Garard, ed., pp. 53-93, Chapman and Hall, London.

Gaze, R. M., and M. Jacobson (1963) A study of the retinotectal projection during regeneration of the optic nerve in the frog. Proc R. Soc. Lond. (Biol.) 157: 420-448.

Gaze, R. M., and M. J. Keating (1970a) Further studies on the restoration of the contralateral retinotectal projection following regeneration of the optic nerve in the frog. Brain Res. 21: 183-195.

Gaze, R. M., and M. J. Keating (1970b) The restoration of the ipsilateral visual projection following regeneration of the optic nerve in the frog. Brain Res. 21: 207-216.

George, S. A., and W. B. Marks (1974) Optic nerve terminal arborizations in the frog: Shape and orientation inferred from electrophysiological measurements. Exp. Neurol. 42: 467-482.

Glastonbury, J., and K. Straznicky (1978) Aberrant ipsilateral retinotectal projection following optic nerve section in Xenopus. Neurosci. Lett. 7: 67-72.

Grobstein, P., and C. Comer (1983) The nucleus isthmi as an intertectal relay for the ipsilateral oculotectal projection in the frog, Rana pipiens. J. Comp. Neurol. 217: 54-74.

Grobstein, P., and T. Masino (1983) Nucleus isthmi in the frog: Connections with monocular tectum. Soc. Neurosci. Abstr. 9: 1166.

Grobstein, P., C. Comer, M. Hollyday, and S. M. Archer (1978) A crossed isthmotectal projection in Rana pipiens and its involvement in the ipsilateral visuotectal projection. Brain Res. 156: 117-123.

Grobstein, P., C. Comer, and S. Kostyk (1980) The potential binocular field and its tectal representation in Rana pipiens. J. Comp. Neurol. 190: 175-185.

Gruberg, E. R., and J. Y. Lettvin (1980) Anatomy and physiology of a binocular system in the frog Rana pipiens. Brain Res. 192: 313-325.

Gruberg, E. R., and S. B. Udin (1978) Topographic projections between the nucleus isthmi and the tectum of the frog Rana pipiens. J. Comp. Neurol. 179: 487500 .

Grüsser, O. J., and U. Grüsser-Cornehls (1976) Neurophysiology of the anuran visual systems. In Frog Neurobiology. A Handbook, R. Llinás and W. Precht, eds., pp. 297-385, Springer-Verlag, New York.

Hollyday, M., and P. Grobstein (1981) Of limbs and eyes and neuronal connectivity. In Studies in Developmental Neurobiology: Essays in Honor of Victor Hamburger, W. M. Cowan, ed., pp. 188-217, Oxford University Press, London.

Horder, T. J. (1971) The course of recovery of the retinotectal projec- tion during regeneration of the fish optic nerve. J. Physiol. (Lond.) 217: 53-54P.

Horder, T. J., and K. A. C. Martin (1978) Morphogenetics as an alternative to chemospecificity in the formation of nerve connections. Symp. Soc. Exp. Biol. 32: 275-358.

Humphrey, M. F., and L. D. Beazley (1982) An electrophysiological study of early retinotectal projection patterns during optic nerve regeneration in Hyla moorei. Brain Res. 239: 595-602.

Hunt, R. K., and M. Jacobson (1974) Neuronal specificity revisited. Curr. Top. Dev. Biol. 8: 203-258.

Jacobson, M., and R. M. Gaze (1965) Selection of appropriate tectal connections by regenerating optic nerve fibers in adult goldfish. Exp. Neurol. 13: 418-430.

Jacobson, M., and R. L. Levine (1975) Stability of implanted duplicate tectal positional markers serving as targets for optic axons in adult frogs. Brain Res. 92: 468-471.

Keating, M. J., and R. M. Gaze (1970) The ipsilateral retinotectal pathway in the frog. Q. J. Exp. Physiol. 55: 284-292.

Kicliter, E., L. J. Misantone, and D. J. Stelzner (1974) Neuronal specificity and plasticity in frog visual system: Anatomical correlates. Brain Res. 82: 293-297.

Khalil, S. H., and G. Lázár (1977) Nucleus isthmi of the frog: Structure and tecto-isthmic projection. Acta Morphol. Acad. Sci. Hung. 25 . $51-59$.

Lettvin, J. Y., H. R. Maturana, W. S. McCulloch, and W. H. Pitts (1959) What the frog's eye tells the frog's brain. Proc. Inst. Rad. Eng. 47: 1940-1951.

Maturana, H. R. (1958) Efferent fibers in the optic nerve of the toad (Bufo bufo). J. Anat. 92: 21-27.

Maturana, H. R., J. Y. Lettvin, W. S. McCulloch, and W. H. Pitts (1960) Anatomy and physiology of vision in the frog (Rana pipiens). J. Gen. Physiol. 43: 129-175.

Meyer, R. L. (1979) Retino-tectal projection in goldfish to an inappropriate region with a reversal in polarity. Science 205: 819-821.

Meyer, R. L. (1980) Mapping the normal and regenerating retino-tectal projection of goldfish with autoradiographic methods. J. Comp. Neurol. 189: 273-289.

Meyer, R. L. (1983) Tetrodotoxin inhibits the formation of refined retinotopography in goldfish. Dev. Brain Res. 6: 293-298.

Meyer, R. I., and R. W. Sperry (1976) Retino-tectal specificity: Chemoaffinity theory. In Neural and Behavioral Specificity, G. Gottlieb, ed., pp. 111-148, Academic Press, Inc., New York.

Northmore, D. P. M., and T. Masino (1984) Recovery of vision in fish after optic nerve crush: A behavioral and electrophysiological study. Exp. Neurol. 84: 109-125.

Schmidt, J. T. (1978) Retinal fibers alter tectal positional markers during the expansion of the half retinal projection in goldfish. J. Comp. Neurol. 177: 279-300.

Schmidt, J. T. (1982) The formation of retinotectal projections. Trends Neurosci. $5:$ 111-116.

Schmidt, J. T., and D. L. Edwards (1982) Activity sharpens the map during the regeneration of the retinotectal projection in goldfish. Soc. Neurosci. Abstr. 8: 668

Sperry, R. W. (1944) Optic nerve regeneration with return of vision in anurans. J. Neurophysiol. 7: 57-69.

Sperry, R. W. (1963) Chemoaffinity in the orderly growth of nerve fiber patterns and connections. Proc. Natl. Acad. Sci. U. S. A. 50: 703-709.

Straznicky, K. (1978) The acquisition of tectal positional specification in Xenopus. Neurosci. Lett. 9: 177-184.

Udin, S. B. (1975) Regeneration in the visual system of Rana pipiens. Ph.D. thesis, Biology Department, Massachusetts Institute of Technology, Cambridge, MA.

Udin, S. B. (1977) Rearrangements of the retinotectal projection in Rana pipiens after unilateral caudal half-tectum ablation. J. Comp. Neurol. 173: 561-582.

Udin, S. B. (1978) Permanent disorganization of the regenerating optic tract in the frog. Exp. Neurol. 58: 455-470. 